\title{
TAILORED CHEMICAL MECHANISMS FOR SIMULATION OF URBAN AIR POLLUTION
}

\author{
LARS MAGNUS T. JOELSSON, CHRISTOFFER PICHLER \& ELNA J. K. NILSSON \\ Department of Physics, Lund University, Sweden
}

\begin{abstract}
A semi-stochastic, statistical reduction method for chemical kinetic schemes based on the ant colony optimization method, is developed for atmospheric chemistry simulations. The prime application is coupled dynamic and chemistry models for simulation of the dispersion and reactivity of chemical species on street scale, i.e. the modelling of urban air pollution in street canyons. The method is designed so that it will optimize the reduction process for any simulation case, as given by user-specific inputs, such as initial concentrations of reactive species, temperature, humidity, residence time, and solar radiation. These inputs will correspond to, or be deduced from, actual variables such as season, time-of-day, geographic location, proximity to volatile organic carbon or nitrogen oxides sources (e.g. forests, roads, industry, harbours etc.) and their source strengths, weather, composition of vehicle fleet, and traffic load inside the street canyon. The method is evaluated against three box model case studies (laboratory and atmospheric simulations) previously described in the literature. The method reduces the mechanism sizes with $62.5 \%, 84.7 \%$, and $97.7 \%$ respectively, retaining the average accuracy for the prediction of the target compound $\left(\mathrm{O}_{3}, \mathrm{NO}_{2}\right.$, and $\left.\mathrm{NO}\right)$ concentrations by $94.1 \%, 90.3 \%$, and $91.2 \%$ respectively. These preliminary results illustrate the potential for the method. Further developments, such as inclusion of lumping or short-cutting of reaction paths, can be considered.

Keywords: modelling, air pollution, reduced chemical kinetic mechanism, ant colony optimization.
\end{abstract}

\section{INTRODUCTION}

From growing concern for greenhouse gas emissions, as well as economic and political reasons, an increasing use of biofuels in the transportation sector over the coming decades can be expected. The shift in usage from fossil to biofuel will change the emission profile from combustion, especially the emission rates of harmful, gas phase, pollutants species such as nitrogen oxides and hydrocarbons [1] and consequently the production rates of secondary pollution species such as ozone [2]. These changes will especially have indications for urban air quality, partly because the confinement of building structures prolongs the residence time of air masses inside the street canyon, and partly because the in-situ pollution sources are likely to be most affected by the shift in fuel composition (i.e. local traffic). The need to accurately predict concentration of these pollutants on urban street scale, e.g. by simulations, is therefore essential in order to provide proper decisions basis for policy-makers.

Simulations of urban air pollution on street scale can be performed either with dynamical models (e.g. CFD models) [3], chemistry box models [4], or coupled models [5]. Plain CFD models (without a chemistry module), which describes mixing and transport of species emitted within the canyon or transported into it, depending on canyon geometry and weather conditions, is arguably the most common approach thus far. Many of the emitted species are, however, reactive on the advection time scales of the street canyon, which means that chemical composition rely also on reactivity. Hence, it has been argued lately that the complexity of the interplay between dynamic and chemical effects within a street canyon demands coupled fluid dynamic and chemistry models [5], which in turn, for computational cost reasons, demand the chemistry scheme to be sufficiently small. The crucial question is therefore: What level of detail needs to be included in the chemical kinetic model to represent the system sufficiently accurate. An important aspect is time and length scales of the system, 
which depend on a set of conditions such as the physical structures, solar radiation, weather, background concentrations and local emissions of reactive species. It is plausible that two optimal chemical kinetic models (optimal with regard to accuracy and computational cost) not would include the same chemistry for different scenarios (e.g. different geographical location, season, time-of-day, or emissions rates). There is no agreement in the literature on the level of detail generally needed for an accurate description of the gas-phase chemistry of air pollution in a street canyon [6], [7].

The main goal of the current study is to develop a method to automatically generate chemical kinetic schemes (henceforth: mechanisms), to be coupled with dynamical models, tailored for the specific sets of conditions of a certain scenario to predict gas-phase air pollution levels. The prime applications is thought to be air pollution simulation on urban street scale, but the method is not restricted to that. The performance of the reduction method is evaluated against three previously described box model case studies: Two alkene photooxidation laboratory studies [8], [9], and an atmospheric $\mathrm{NO}_{x}-\mathrm{VOC}$ simulation [10].

\subsection{Tropospheric chemistry}

\section{BACKGROUND}

The compounds of interest in tropospheric chemistry from a human health perspective is arguably nitrogen dioxide, ozone, carbon monoxide, and volatile organic carbons (VOCs) [11], [12]. Carbon monoxide has such long chemical lifetime in the troposphere (on the order of months) that it can be considered insert on a street scale [2]. Nitrogen dioxide is readily photolyzed in the troposphere to yield nitric oxide and ozone:

$$
\begin{gathered}
\mathrm{NO}_{2}+h \nu \rightarrow \mathrm{NO}+\mathrm{O}, \\
\mathrm{O}+\mathrm{O}_{2} \rightarrow \mathrm{O}_{3}+\mathrm{M} .
\end{gathered}
$$

Nitric oxide and ozone recombines to give back nitrogen dioxide.

$$
\mathrm{NO}+\mathrm{O}_{3} \rightarrow \mathrm{NO}_{2}+\mathrm{O}_{2} \text {. }
$$

The rather fast cycling described by eqns (1)-(3) makes it applicable to use the chemical family term of nitrogen oxides $\left(\mathrm{NO}_{x}=\mathrm{NO}_{2}+\mathrm{NO}\right)$. Nitrogen oxides are mainly emitted from combustion processes, while eqn (2) is the main source of ozone. The key to ozone production is therefore partly the rate at which nitrogen dioxide is photolyzed, depending on solar radiation, partly on the rate at which nitric oxide is converted to nitrogen dioxide. This rate can be enhanced from the resulting rate of the $\mathrm{NO}_{x}-\mathrm{O}_{3}$ system described above, but also by reactions with peroxy radicals $\left(\mathrm{HO}_{2}\right.$ and $\mathrm{RO}_{2}$, where $\mathrm{R}$ is an alkyl group). Peroxy radicals are generated in the oxidation chain of hydrocarbons, thus the presence of hydrocarbons in a chemical system will induce production of ozone. The main sink of nitrogen oxides is the oxidation with hydroxal radicals to form nitric acid, which might be removed out of the system by condensation.

\subsection{Coupled street canyon studies}

The first study of the dispersion and transport of reactive pollutants in a street canyon model used a large eddy simulation (LES) with a (pseudo) two reaction $\mathrm{NO}_{x}-\mathrm{O}_{3}$ system described by eqns (1)-(3) [13]. Eqns (1) and (2) can be treated as a single reaction: $\mathrm{NO}_{2}+h \nu+\mathrm{O}_{2} \rightarrow$ $\mathrm{NO}+\mathrm{O}_{3}$. Such collection of reactions will henceforth be called a photostationary steady state (PSS) mechanism. The PSS chemical description in coupled models is frequently used 
throughout the coupled modelling literature, hence discarding any effect of hydrocarbon- or hydrogen oxide radicals $\left(\mathrm{HO}_{x}=\mathrm{OH}+\mathrm{HO}_{2}\right)$ chemistry. Different aspects of street canyon systems, as the effects of shading [14], bottom heating [15], [16], building height to street width ratio [17], and even roof greening [18] has been studied with similar setups.

The effect of hydrocarbons on ozone- and nitric oxide-levels was first studied using a chemical module with the Carbon Bond Mechanism IV (CBM-IV) [6]. The different reduced scheme are described briefly in Section 2.3. No significant impact of hydrocarbon- or $\mathrm{HO}_{x^{-}}$ chemistry on ozone- and nitrogen dioxide-levels was found in these simulations. In contrast, a simulation study involving the GEOS-Chem model shows that hydrocarbon chemistry, more precisely VOC oxidation, plays an important role for ozone levels, especially in less polluted environments [24].

The coupled behaviour of the chemical system is further pronounced in a study where the results of a chemistry box model are compared to those of a coupled model, both using the Reduced Chemical Scheme (RCS) [10]. The box model underestimates ozone and overestimates nitrogen oxides and hydroxyl radical concentration levels compared to the coupled model. These discrepancies are attributed to segregation effects, which arises when the mixing timescales are longer than the chemical timescales, such that mixing of the reactive species is not complete and local concentrations of two reactants in a reaction might be anti-correlated in space. Accordingly, this reduces the effect of the reaction described by eqn (3), and also the mean hydroxyl radical reactivity in the study. The sensitivity of nitrogen oxides levels on traffic emission- and weather conditions are further investigated in a study where three different levels on chemistry simulation complexity on a set of scenarios were compared [7]. It was found that nitric oxide concentration was insensitive to the inclusion of VOC chemistry under typical winter conditions, but not in situations where ozone levels were relatively high. In conclusion, no consensus has so far been reached in this relatively novel research field considering the most appropriate approach regarding the chemistry description in coupled models. It seems, however, that a flexible approach, sensitive towards external factors, should have some benefits.

\subsection{Reduced mechanism}

There are a few reduced chemical mechanisms ocurring in the literature, some described in a comprehensive review of coupled street canyon modelling [5], some described in a review of chemical mechanisms used in global models [22]. Perhaps the first mechanism including both VOC and $\mathrm{NO}_{x}$ chemistry used in urban street canyon modelling was the Generalized VOCs and $\mathrm{NO}_{x}$ mechanism [2], [4], which contains 23 species and 20 reactions. The reduction follows a rather basal idea where the compounds are lumped according to functional groups, e.g. $\mathrm{RO}_{2}$ for all peroxy radicals, $\mathrm{RCHO}$ for all aldehydes etc.

Several studies [6], [19]-[21] utilizes the CBM-IV [23], a lumped chemical mechanism covering 28 species and 81 reactions. The mechanism is a further reduction of the The Detailed Carbon Bond Mechanism (CBM-EX), generated by the structural-lumping technique. Organic species are represented by one or a linear combination of surrogate species defined according to their carbon bond types, e.g. single-bonded one-carbon-atom are represented by the surrogate PAR and the carbon-carbon double bond found for example in 1-alkenes is represented by the surrogate OLE (olefins). Thus, the alkene propene $\left(\mathrm{C}_{3} \mathrm{H}_{6}\right)$ is represented as 1 OLE + 1 PAR, the alkane n-butane is represented as 4 PAR, and so on. The mechanisms are explicitly developed for simulations of urban and regional photochemistry.

GEOS-Chem, which chemistry module is employed in some studies [24], is a global 3-D chemical transport model. The chemistry module includes major anthropogenic hydrocarbons and isoprene, all in all 110 species and 343 reactions. 
The box model case, used as a bench-mark for the current study, is originally evaluated using the RCS, a reduction of the Common Representative Intermediate (CRI) mechanism, which in turn is derived from MCM using a lumped structure technique. The RCS which is reduced by sensitivity and scaled to retain OH-reactivity, covers 51 species and 136 reactions [10].

Finally, a more recent study [7] let develop the Complex Chemical Mechanism (CCMCFD) to be used with a CFD model, with the software CHEMATA (CHEmical Mechanism Adaptation to Tropospheric Applications) [25] from the Regional Atmospheric Chemistry Mechanism (RACM). CHEMATA takes a list of species and their source strengths (emissions or atmospheric production), kinetic data and lumping group definitions as inputs and automatically generate tailored mechanisms.

\section{METHOD}

The current study uses a semi-stochastic, statistical reducing method based on the Ant Colony Optimization (ACO) concept [26]. The reducing method is originally developed for combustion physics applications. The basic idea of the method is to build a reduced chemical mechanism by semi-stochastically select a number of reactions from a full set of reactions describing a chemical system. In the current study the near-explicit chemical mechanism Master Chemical Mechanism (MCM v3.3.1) [27]-[29], comprised of 16,701 reactions and 5,832 species, is used as the full mechanism (base mechanism). The perhaps most notable approximation of MCM, besides the omission of relatively slow reaction channels, is the simplification of the peroxy radical-peroxy radical reaction description, where each peroxy radical reacts with the pool of peroxy radicals represented by a symbolic peroxy species and where the reaction rate coefficient have a generic value.

The reduced chemical mechanism is used as input in a chemical box model with a certain set of initial conditions, such as temperature, relative humidity, and initial concentration of chemical compounds. The model used in the current study is a version of the chemical module of the Aerosol Dynamics, gas- and particle-phase chemistry model for laboratory CHAMber studies (ADCHAM) model [31], where the aerosol sub-module is omitted. The model uses a modified version of the Kinetic Pre-Processor (KPP) solver [30].

The results of the box model simulation over a certain time period are evaluated against some benchmark, (here the results of a full-model run, but it might as well be measurements). The performance (ability to predict target compound concentration compared to the benchmark) and size of mechanisms for which the performance exceeds a given acceptance threshold (accepted mechanisms) adjusts the reactions weight (by a so-called "pheromone"-value) in the selection process, such that the selected mechanism iteratively will converge towards an optimal mechanism.

The selection process is designed as such: All reaction with one of the initial species as reactants are listed. The reactions are ascribed weights calculated from a combination of static "rate-of-production"-values and dynamic "pheromone"-values. A reaction's "rateof-production"-value is obtained from the rate of production of products as found in the full model (benchmark) run (here: the rate of production at half the simulation time). The "pheromone"-value is calculated from the performance and size of accepted chemical mechanisms: Each reaction has a "pheromone"-value ascribed to it, which it carries throughout the entire reduction process. Every time a mechanism is accepted, a value based on the performance and size of the mechanism is added to the all included reactions' "pheromone"-values. Reactions important for an accurate description on the chemical system will hence gain more weight through the reduction process compared to less important reactions. A reaction is stochastically selected according to their weight (hence semi- 
stochastic). An element of the reactant is ascribed to one of the products of the reaction and this product is now considered the starting compound of the selection process as the process starts over, following the element's path through the chemical system. The process terminates when the element is transferred to one of the given end products (e.g. carbon dioxide or water vapour). The process starts over with the next element in the same initial species, and then with the next initial species, until all the elements in all the initial species have been tracked. If a given minimum limit of steps (i.e. reactions in the specific path, since one reaction might be included in several paths, the term "steps" is used here) is not exceeded, the process will start over until the minimum limit condition is satisfied. If a maximal limit of steps are exceeded, the ant will be discarded. The set of reactions collected through this process makes up the reduced chemical mechanism. The mechanism is evaluated by the model and is given an (average) root-mean-square (RMS) score, see eqn (4). If the score exceeds an acceptance threshold, the mechanism is accepted and it's performance and size will contribute to the next "pheromone"-value update.

The average root-mean-square (RMS) score of the target compounds $(\mathrm{X}, \mathrm{Y}, \ldots, \mathrm{Z})$ is defined as:

$$
\text { score }=\frac{1}{n} \sum_{\mathrm{A}=\mathrm{X}_{1}, \mathrm{X}_{2}, \ldots, \mathrm{X}_{n}} 1-\sqrt{\overline{\left(\frac{[\mathrm{A}]}{[\mathrm{A}]_{\text {benchmark }}}-1\right)^{2}}},
$$

where $[\mathrm{A}]$ is the concentration of target compound $\mathrm{A}$ is calculated for each intermediate mechanism against the benchmark full model run.

The relative importance of the two weights ("rate-of-production" and "pheromone") is decided by two exponential "weight-of-weights"-parameters, ascribed to each of the weights. These two parameters add degrees of freedom to the selection process along with an "evaporation"-parameter, which determines a rate at which the "pheromone"-value is reduced over time for the reactions, a parameter determining the total sum of "pheromone" distributed by each ant, limits for minimal and maximal steps taken in the reduction process, the acceptance threshold for the mechanisms' performance, and finally the number och ants run between each "pheromone"-update (an "epoch"). The limits for the minimal and maximal steps taken vary considering the number of accepted mechanisms in the epoch and the acceptance threshold can be set to be progressive, so that the threshold for acceptance increases with passing epochs. Moreover, the procedure to determine the "rateof-production"-values and the definition of end species will influence the outcome of the method. For example, if short time scales are considered, the oxidation chain of hydrocarbons might not be expected to reach carbon dioxide and it is perhaps advisable to include carbon monoxide or even formaldehyde as end species to avoid a "back-end" heavy mechanism. Finally, the selection of target compounds tunes the method towards mechanism that predict these compounds, the method is not restricted to those target compounds that happen to be named in the case studies below.

The ACO-reduction method is evaluated against two chamber experiments of the photooxidation of alkenes (propene and 1-butene respectively), previously modelled with the full MCM (although with an earlier version: v3.1) [8], [9] and an atmospheric $\mathrm{NO}_{x}-\mathrm{VOC}$ photochemistry study (including eight VOCs, nitrogen oxides, ozone, carbon monoxide, nitric acid, methane, and water vapour) with initial concentration taken from the TORCH field campaign [32]. The box model is previously used to evaluate the RCS mechanism against the full MCM [10]. The relevant part of the MCM covers 251 reactions, including 14 extra reactions specific for the laboratory setting (wall effects etc.) and 84 species, including two specific for wall effects, 321 reactions, including 13 extra reactions and 108 species, including two specific for wall effects, and 1,923 reactions and 608 species respectively for the three 

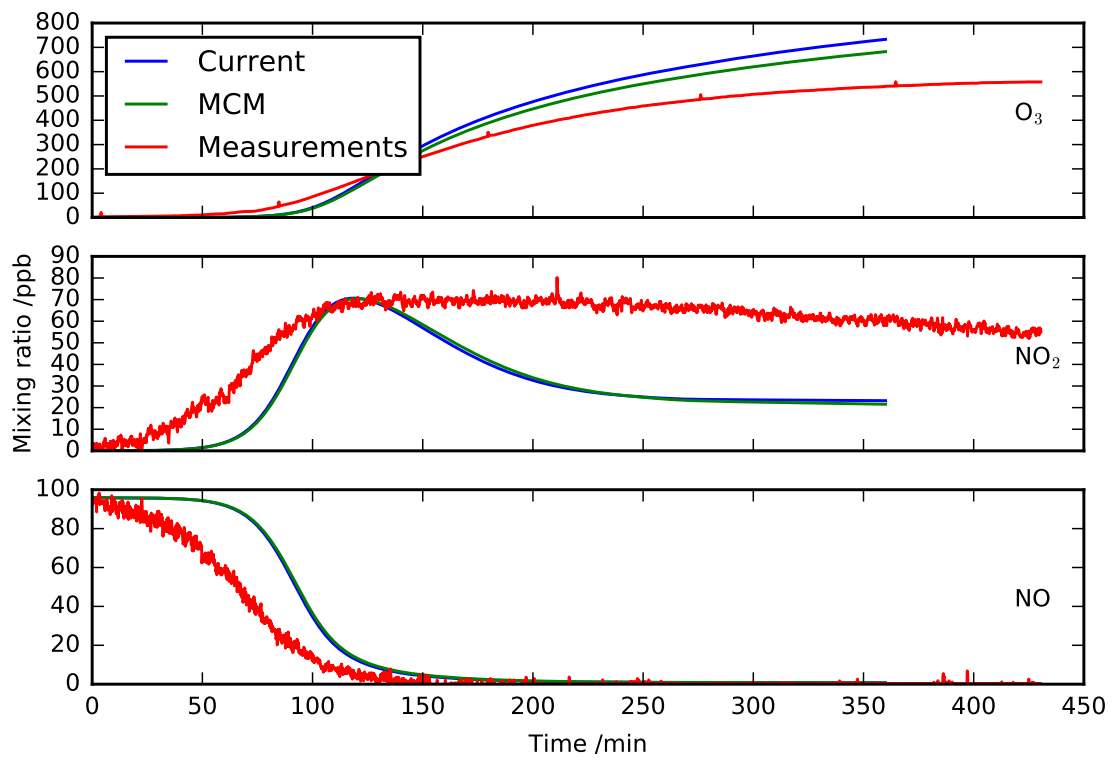

Figure 1: The simulated (measured) mixing ratio of the target compounds (from top to bottom: $\mathrm{O}_{3}, \mathrm{NO}_{2}$, and $\mathrm{NO}$ ) against simulation (measurement) time of a laboratory study of the photo-oxidation of propene. The blue lines correspond to simulation with the mechanism generated by the current method ( 94 reactions and 56 species), the green lines correspond to MCM (251 reactions and 84 species), and the red line correspond to the continuous measurements.

cases. These subset thus correspond to the full MCM. Just shy of 100,000 mechanisms are generated and tested for each case in the progress, the "pheromone"-value is updated every 150 mechanism. The photolysis coefficients are in the case of propane and 1-butane simulations set to mimic the effect of the lightning modules of the Commonwealth Scientific and Industrial Research Organisation (CSIRO) laboratory and are supplied by Dr Stephen J. White (stephen.j.white@ csiro.au) 14 Dec. 2017. The photolysis coefficient of the $\mathrm{NO}_{x}-\mathrm{VOC}$ simulation is given by the ADCHAM model.

Three mechanisms are selected from these (the smallest mechanism with an accuracy loss less than 10\%), one for each case, are evaluated against current MCM simulations and compared with measurements where these are available (i.e. for the alkene photo-oxidation experiments) or the PSS set of reactions where this is applicable (i.e. for the $\mathrm{NO}_{x}-\mathrm{VOC}$ photochemistry study). The measurements were either conducted with a UV photometric analyser $\left(\mathrm{O}_{3}\right)$ or a chemiluminescence analyser $\left(\mathrm{NO}_{2}\right.$ and $\left.\mathrm{NO}\right)$ [8].

\section{RESULTS AND DISCUSSION}

The ACO-based reduction algorithm is run for three box model cases: Simulations of the laboratory studies of photo-oxidation of propane, 1-butane [8], [9], and an atmospheric $\mathrm{NO}_{x}-$ VOC photochemistry study [10], [32]. The smallest mechanisms (94 reactions and 56 species, 49 reactions and 36 species, and 44 reactions and 37 species respectively) with an average accuracy loss less than $10 \%(5.9 \%, 9.7 \%$, and $8.8 \%$ respectively) for each case are selected and 

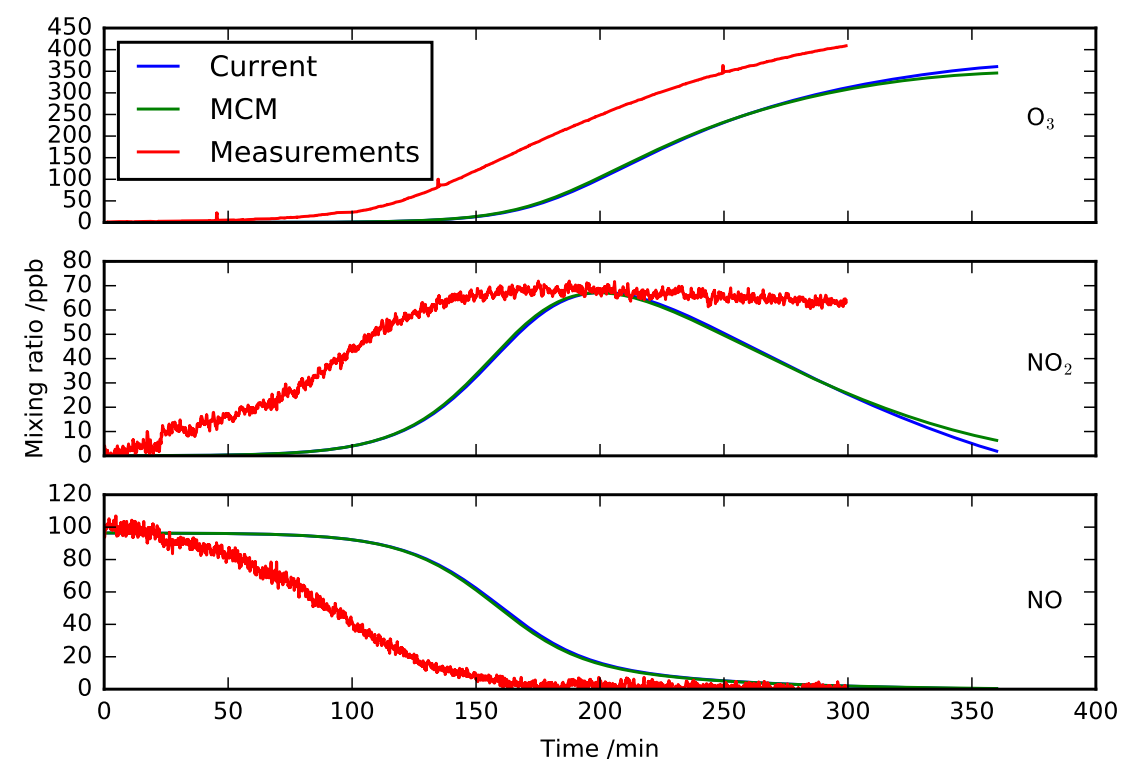

Figure 2: The simulated (measured) mixing ratio of the target compounds (from top to bottom: $\mathrm{O}_{3}, \mathrm{NO}_{2}$, and $\mathrm{NO}$ ) against simulation (measurement) time of a laboratory study of the photo-oxidation of 1-butene. The blue lines correspond to the simulation with the mechanism generated by the current method (49 reactions and 36 species), the green lines correspond MCM (321 reactions and 108 species), and the red line correspond to the continuous measurements.

the target concentrations are plotted in Figs 1-3, respectively. By simple process time statistic, the computational time is estimated to be reduced by $49 \%, 78 \%$, and $95 \%$ respectively.

The whole distribution of RMS score against mechanism size for all accepted mechanisms are given in Fig. 4. Note that other mechanisms could have been chosen out of this distribution given other selection criteria, (i.e. higher accuracy or smaller mechanism sizes). To give an insight in the convergence process, the RMS-scores and the mechanism sizes are plotted against the order of acceptance (i.e. chronologically ordered) in Fig. 5.

The best mechanism simulation of the photo-oxidation of propane case (Fig. 1) yield a prediction for $\left[\mathrm{O}_{3}\right],\left[\mathrm{NO}_{2}\right]$, and $[\mathrm{NO}]$ which deviates on average $7.1 \%, 4.2 \%$, and $6.4 \%$ respectively, over the entire $6 \mathrm{~h}$ period. The corresponding numbers for the 1-butene case (Fig. 2) is $2.9 \%, 12.1 \%, 13.9 \%$ respectively. Generally the largest deviations are toward the end of the simulations. Evidently, the simulations does not reproduce the measure results perfectly, although this is also true for the full MCM run. Since the method is tuned to reproduce the MCM results, any other outcome would not be expected. The average deviation of the $\mathrm{NO}_{x}-\mathrm{VOC}$ case (Fig. 3) is $6.7 \%, 10.5 \%$, and $9.3 \%$ for $\left[\mathrm{O}_{3}\right],\left[\mathrm{NO}_{2}\right]$, and [NO] respectively. As can be seen in Fig. 3, the PSS is not adequate to reproduce these concentrations.

It remains unclear why the method delivers larger mechanisms for the propene case than for the 1-butene and $\mathrm{NO}_{x}-\mathrm{VOC}$ cases. Note that this is not merely in relative numbers, but 


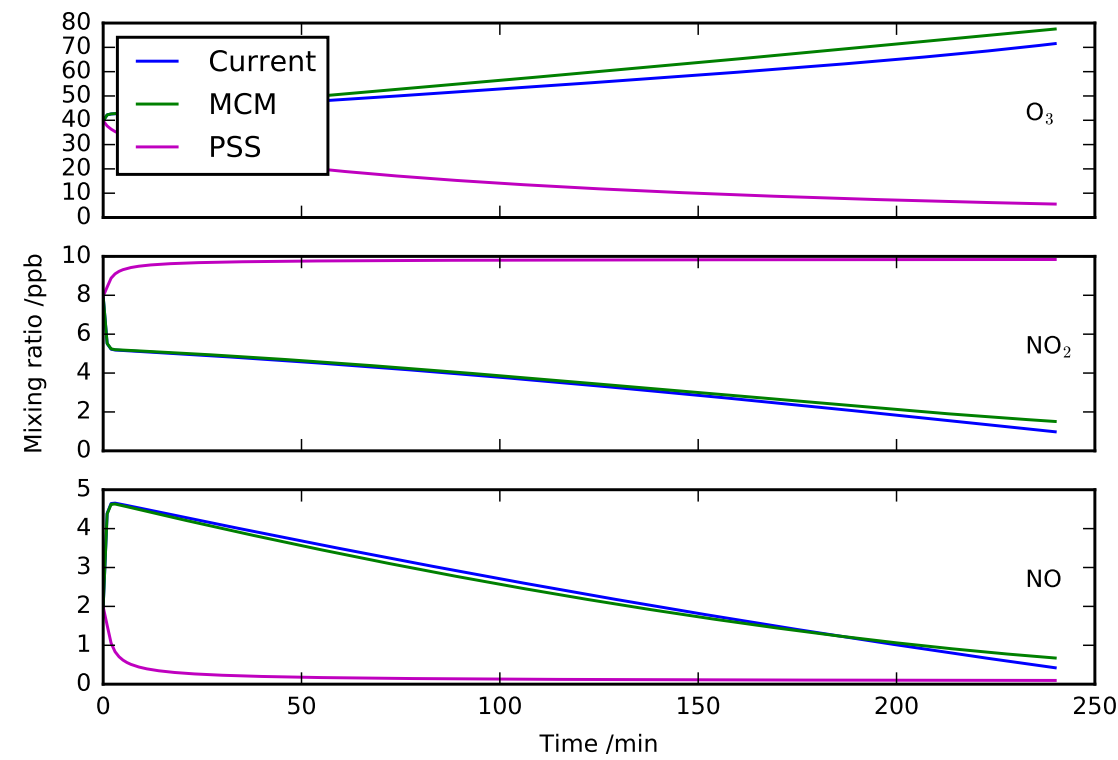

Figure 3: The simulated mixing ratio of the target compounds (from top to bottom: $\mathrm{O}_{3}, \mathrm{NO}_{2}$, and NO) against simulation time of an atmospheric $\mathrm{NO}_{x}-\mathrm{VOC}$ photochemical study. The blue lines correspond to the simulation with the mechanism generated by the current method (44 reactions and 37 species), the green lines correspond to MCM (1,924 reactions and 608 species), and the magenta line correspond to the PSS set of reactions.

also in absolute numbers, as can be seen in Fig. 4. It is probable that the method parameters (especially the "weight-of-weights") are sub-optimally chosen. Clearly, the reduction process does not converge the mechanism size in the case of the propene study, as opposed to the two other studies, see Fig. 5. Note that the acceptance threshold progressively increases throughout the process, which partly explains the convergence of RMS-score.

After the evaluation of just under 100,000 mechanisms, the method delivers mechanisms accurate and small enough to be included in CFD models, at least for the cases tested. For instance, the RCS, employed in the $\mathrm{NO}_{x}-\mathrm{VOC}$ box model simulation used as a benchmark for this study, as well as in the coupled LES-RCS model, includes 136 chemical reactions and 51 species, compared to the 44 reactions and 37 species large mechanism generated by the current method for the corresponding case. The deviation between the mechanism generated with the current method and MCM at the 30-min mark is $2.4 \%, 1.0 \%$, and $2.2 \%$ for $\mathrm{O}_{3}$, $\mathrm{NO}_{2}$, and NO respectively. The corresponding numbers for RCS is $0.2 \%, 0.1 \%$, and $0.4 \%$ respectively [10].

The method has so far only been implemented to reduce (near-) explicit base mechanisms (subsets of MCM), but there is no obvious reason to why the reduction process should not be valid also for lumped base mechanisms or that a post-process lumping procedure could be added to it. Further development therefore includes enabling the usage of lumped mechanism as a starting point or incorporate some automatic lumping algorithm. Another very attractive 

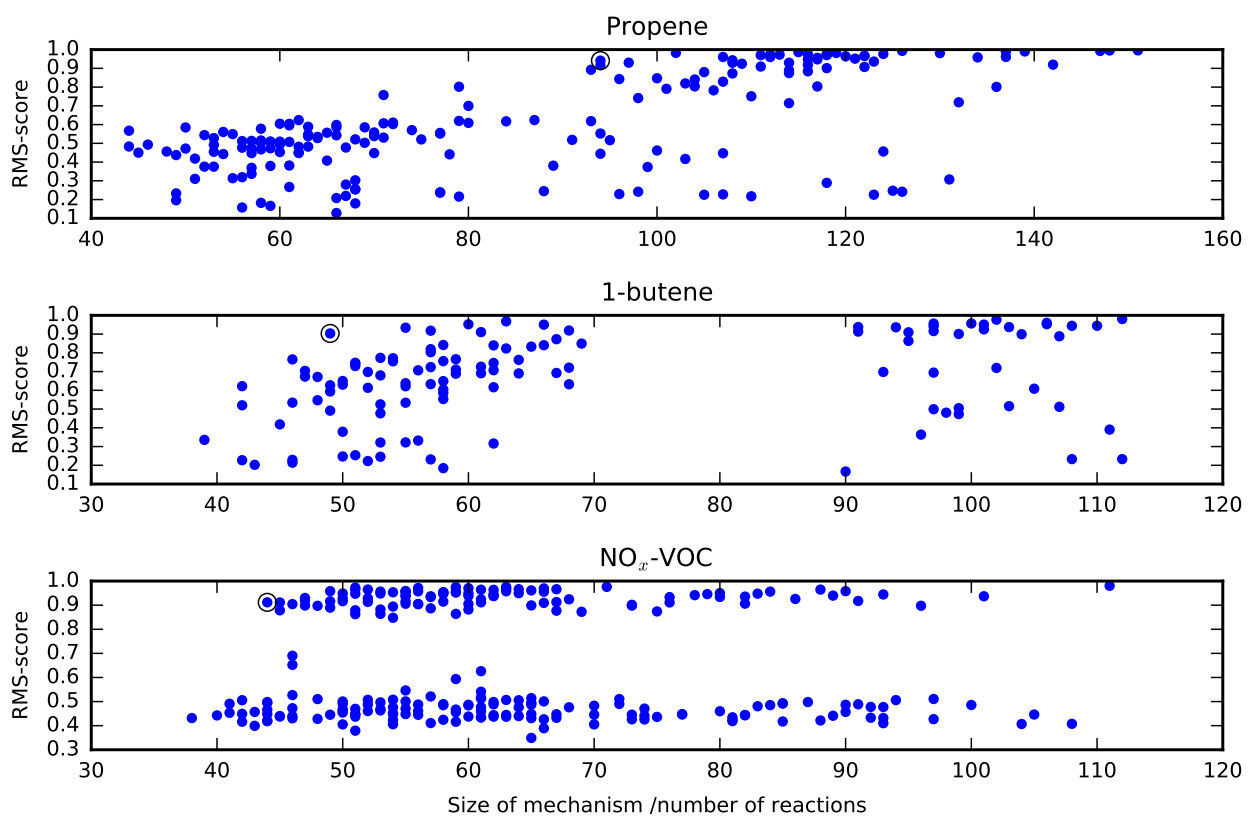

Figure 4: Average root-mean-square score of target compound $\left(\mathrm{O}_{3}, \mathrm{NO}_{2}\right.$, and $\left.\mathrm{NO}\right)$ concentrations against relative size of reduced mechanism for all accepted mechanisms of the three runs of the method: Simulation of photo-oxidation laboratory studies propene (top), with the maximal number of reactions at 251, and 1-butene (middle), with the maximal number of reactions at 321, and an atmospheric $\mathrm{NO}_{x}-\mathrm{VOC}$ photochemistry simulation (bottom), with the maximal number of reactions at 1,924 . The dots corresponding to the selected mechanisms are encircled.

alternative for further development that currently is being considered is to identify temporal short or deterministic intermediate steps in the different reaction paths and give the selection process alternative short-cut routes through the mechanism in these areas. Finally, a two stage approach, where a relatively large and accurate mechanism would first be generated and then used as the base mechanism for a second reduction process, might render a more effective reduction process, overall.

\section{CONCLUSION}

An ant colony optimization-based chemistry mechanism reduction method is developed for atmospheric chemistry applications, especially urban street canyon air pollution simulations. The method yield chemistry kinetic mechanism optimized for certain conditions. The method is tested in three cases (two relatively small laboratory study simulations and one larger atmospheric study) and mechanism with the number of reactions reduced to $62.5 \%, 84.7 \%$, and $97.7 \%$ respectively, compared to the original mechanism, and with the accuracy loss of $5.9 \%, 9.7 \%$, and $8.8 \%$ respectively in target concentration predictions are delivered by the method. Further development might include lumping or automatic reaction path shortcutting. 

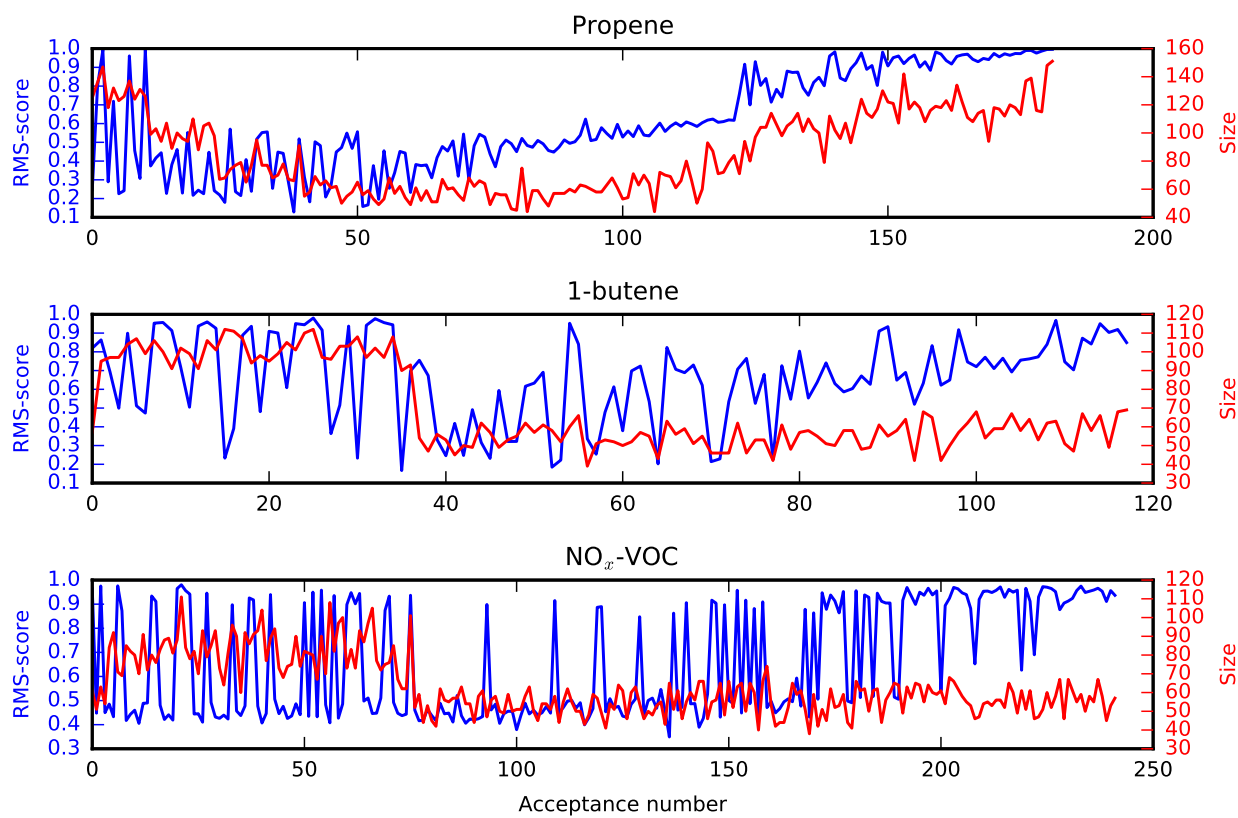

Figure 5: Average root-mean-square score of target compound $\left(\mathrm{O}_{3}, \mathrm{NO}_{2}\right.$, and $\left.\mathrm{NO}\right)$ concentrations (left, blue) and size (right, red) of reduced mechanism against order of acceptance (chronologically ordered) for all accepted mechanisms of the three runs of the method: simulation of photo-oxidation laboratory studies propene (top) and 1-butene (middle), and an atmospheric $\mathrm{NO}_{x}-\mathrm{VOC}$ photochemistry simulation (bottom).

\section{ACKNOWLEDGEMENTS}

Dr Pontus Roldin, Lund University, and Dr Sampo Smolander, Princeton University, for the development of the chemistry box model solver. Dr Dennys E. Angove, Sydney Mechanics' School of Arts, and Dr Stephen J. White, Commonwealth Scientific and Industrial Research Organisation, for the model and measurement data from the alkene photo-oxidation studies.

\section{REFERENCES}

[1] Hoekman, S.K. \& Robbins, C., Review of the effects of biodiesel on $\mathrm{NO}_{x}$ emissions. Fuel Processing Technology, 96, pp. 237-249, 2012.

[2] Seinfeld, J. \& Pandis, S., Atmospheric Chemistry and Physics, Wiley: Hoboken, NJ, 2016.

[3] Vardoulakis, S., Fisher, B., Pericleous, K. \& Gonzalez-Flesca, N., Modelling air quality in street canyons: a review. Atmospheric Environment, 37(2), pp. 155-182, 2003.

[4] Liu, C. \& Leung, D., Numerical study on the ozone formation inside street canyons using a chemistry box model. Journal of Environmental Sciences, 20(7), pp. 832-837, 2008.

[5] Zhong, J., Cai, X. \& Bloss, W., Coupling dynamics and chemistry in the air pollution modelling of street canyons: a review. Environmental Pollution, 214, pp. 690-704, 2016. 
[6] Garmory, A., Kim, I., Britter, R. \& Mastorakos, E., Simulations of the dispersion of reactive pollutants in a street canyon, considering different chemical mechanisms and micromixing. Atmospheric Environment, 43(31), pp. 4670-4680, 2009.

[7] Sanchez, B., Santiago, J., Martilli, A., Palacios, M. \& Kirchner, F., CFD modelling of reactive pollutant dispersion in simplified urban configurations with different chemical mechanisms. Atmospheric Chemistry and Physics, 16(18), pp. 12143-12157, 2016.

[8] Hynes, R.G., Angove, D.E., Saunders, S.M., Haverd, V. \& Azzi, M., Evaluation of two MCM v3. 1 alkene mechanisms using indoor environmental chamber data. Atmospheric Environment, 39(38), pp. 7251-7262, 2005.

[9] Ginnebaugh, D.L., Liang, J. \& Jacobson, M.Z., Examining the temperature dependence of ethanol (E85) versus gasoline emissions on air pollution with a largely-explicit chemical mechanism. Atmospheric Environment, 44(9), pp. 1192-1199, 2010.

[10] Bright, V.B., Bloss, W.J. \& Cai, X., Urban street canyons: coupling dynamics, chemistry and within-canyon chemical processing of emissions. Atmospheric Environment, 68, pp. 127-142, 2013.

[11] Health aspects of air pollution with particulate matter, ozone and nitrogen dioxide. WHO Regional Office for Europe: Copenhagen, 2003.

[12] Ambient Air Pollution: Pollutants. World Health Organization. Online. http://www.who.int/airpollution/ambient/pollutants/en/. Accessed on: 26 Feb. 2018.

[13] Baker, J., Walker, H. \& Cai, X., A study of the dispersion and transport of reactive pollutants in and above street canyons-a large eddy simulation. Atmospheric Environment, 38(39), pp. 6883-6892, 2004.

[14] Grawe, D., Cai, X. \& Harrison, R., Large eddy simulation of shading effects on $\mathrm{NO}_{2}$ and $\mathrm{O}_{3}$ concentrations within an idealised street canyon. Atmospheric Environment, 41(34), pp. 7304-7314, 2007.

[15] Baik, J., Kang, Y. \& Kim, J., Modeling reactive pollutant dispersion in an urban street canyon. Atmospheric Environment, 41(5), pp. 934-949, 2007.

[16] Kang, Y., Baik, J. \& Kim, J., Further studies of flow and reactive pollutant dispersion in a street canyon with bottom heating. Atmospheric Environment, 42(20), pp. 4964-4975, 2008.

[17] Tong, N.Y.O. \& Leung, D.Y.C., Effects of building aspect ratio, diurnal heating scenario, and wind speed on reactive pollutant dispersion in urban street canyons. Journal of Environmental Sciences, 24(12), pp. 2091-2103, 2012.

[18] Moradpour, M., Afshin, H. \& Farhanieh, B., A numerical investigation of reactive air pollutant dispersion in urban street canyons with tree planting. Atmospheric Pollution Research, 8(2), pp. 253-266, 2017.

[19] Kwak, K.-H. \& Baik, J.-J., A CFD modelling study of the impacts of $\mathrm{NO}_{x}$ and VOC emissions on reactive pollutant dispersion in and above a street canyon. Atmospheric Environment, 46, pp. 71-80, 2012.

[20] Kwak, K.-H., Baik, J.-J. \& Lee, K.-Y., Dispersion and photochemical evolution of reactive pollutants in street canyons. Atmospheric Environment, 70, pp. 98-107, 2013.

[21] Kwak, K.-H. \& Baik, J.-J., Diurnal variation of $\mathrm{NO}_{x}$ and ozone exchange between a street canyon and the overlying air. Atmospheric Environment, 86, pp. 120-128, 2014.

[22] Emmerson, K.M. \& Evans, M.J., Comparison of tropospheric gas-phase chemistry schemes for use within global models. Atmospheric Chemistry and Physics, 9(5), pp. 1831-1845, 2009.

[23] Gery, M.W., Whitten, G.Z., Killus, J.P. \& Dodge, M.C., A photochemical kinetics mechanism for urban and regional scale computer modelling. Journal of Geophysical Research: Atmospheres, 94(D10), pp. 12925-12956, 1989. 
[24] Kim, M.J., Park, R.J. \& Kim, J.-J., Urban air quality modelling with full $\mathrm{O}_{3}-\mathrm{NO}_{x}-$ VOC chemistry: implications for $\mathrm{O}_{3}$ and $\mathrm{PM}$ air quality in a street canyon. Atmospheric Environment, 47, pp. 330-340, 2012.

[25] Kirchner, F., The chemical mechanism generation programme CHEMATA-Part 1: the programme and first applications. Atmospheric Environment, 39(6), pp. 1143-1159, 2005.

[26] Dorigo, M. \& Birattari, M., Ant colony optimization. Encyclopedia of Machine Learning. Springer: Boston, MA, pp. 36-39, 2011.

[27] Jenkin, M.E., Saunders, S.M. \& Pilling, M.J., The tropospheric degradation of volatile organic compounds: a protocol for mechanism development. Atmospheric Environment, 31(1), pp. 81-104, 1997.

[28] Saunders, S.M., Jenkin, M.E., Derwent, R.G. \& Pilling, M.J., Protocol for the development of the Master Chemical Mechanism, MCM v3 (Part A): tropospheric degradation of non-aromatic volatile organic compounds. Atmospheric Chemistry and Physics, 3(1), pp. 161-180, 2003.

[29] The Master Chemical Mechanism. University of Leeds. Online. http://mcm.leeds.ac.uk/MCM. Accessed on: 26 Feb. 2018.

[30] Damian, V., Sandu, A., Damian, M., Potra, F. \& Carmichael, G.R., The Kinetic PreProcessor KPP - a software environment for solving chemical kinetics. Computers and Chemical Engineering, 26(11), pp. 1567-1579, 2002.

[31] Roldin, P., Eriksson, A.C., Nordin, E.Z., Hermansson, E., Mogensen, D., Rusanen, A. et al., Modelling non-equilibrium secondary organic aerosol formation and evaporation with the aerosol dynamics, gas-and particle-phase chemistry kinetic multilayer model ADCHAM. Atmospheric Chemistry and Physics, 14(15), pp. 7953-7993, 2014.

[32] Lee, J.D., Lewis, A.C., Monks, P.S., Jacob, M., Hamilton, J.F., Hopkins, J.R. et al., Ozone photochemistry and elevated isoprene during the UK heatwave of August 2003. Atmospheric Environment, 40(39), pp. 7598-7613, 2006. 